\title{
Aplicações do empreendedorismo na conservação ambiental dos recursos naturais
}

A relação sociedade/natureza utilizando a metodologia do materialismo histórico e dialético, bem como essas relações e a questão ambiental mediante o conhecimento do processo de produção do espaço, considerou a produção como um processo pelo qual o homem, por intermédio de seu trabalho, modifica as formas de satisfazer suas necessidades, criando assim, valores de uso. Identificar os benefícios econômicos sociais e ambientais gerados a partir do conhecimento dos produtos florestais gera benefícios aos atores envolvidos ao estimular novas relações, propiciando a criação de novos negócios na região, impulsionando ações voltadas ao desenvolvimento sustentável gerando mútuos benefícios. A pesquisa aponta que o empreendedorismo aplicado a análises econômicas bem planejadas e um estudo da melhor utilização dos recursos naturais podem ser trabalhados à medida que as dimensões da sustentabilidade são consideradas. A cadeia produtiva de um determinado produto extrativista, no caso o açaí (Euterpe oleraceae), pode ser um bom indicativo de que o produtor/empreendedor consiga aumentar sua renda e conservar o meio ambiente em que vive. O estudo de potencialidades regionais propalado pela Superintendência da Zona Franca de Manaus indica a possibilidade de se operar um bom estudo de viabilidade econômica que potencialize a oportunidade de geração de renda e melhor distribuição de riquezas com foco no empreendedorismo e na melhor utilização dos produtos extrativos.

Palavras-chave: Açaí; Benefícios Econômicos; Sociedade; Sustentabilidade.

\section{Applications of entrepreneurship in environmental conservation of natural resources}

The relation between society and nature using the methodology of historical and dialectical materialism, as well as these relations and the environmental question through the knowledge of the process of production of space, considered production as a process by which man, by means of his work, modifies the ways of satisfying their needs, thus creating values of use. Identifying the social and environmental economic benefits generated from the knowledge of forest products generates benefits to the actors involved by stimulating new relationships, propitiating the creation of new businesses in the region, promoting actions aimed at sustainable development generating mutual benefits. The research points out that entrepreneurship applied to well-planned economic analyzes and a study of the best use of natural resources can be worked out as the dimensions of sustainability are considered. The productive chain of a particular extractive product, in the case açai (Euterpe oleraceae), can be a good indication that the producer/entrepreneur is able to increase his income and conserve the environment in which he lives. The study of regional potential offered by Superintendência da Zona Franca de Manaus indicates the possibility of operating a good economic feasibility study that will enhance the opportunity to generate income and better distribution of wealth with a focus on entrepreneurship and the best use of extractive products.

Keywords: Açaí; Economic Benefits; Society; Sustainability.

Topic: Uso de Recursos Naturais

Reviewed anonymously in the process of blind peer
Received: 03/02/2021

Approved: 26/02/2021
Carlos Sérgio da Silva Guimarães

Universidade Federal do Amazonas, Brasil http://lattes.cnpq.br/2450432446736949 cssguima@gmail.com

Marcos André Braz Vaz

Universidade Federal do Amazonas, Brasil http://lattes.cnpq.br/4734503770986416 http://orcid.org/0000-0002-9135-7763

marcosvaz@ufam.edu.br

Rafael Bel Prestes da Silva (ic

Universidade Federal de Santa Maria, Brasil http://lattes.cnpq.br/9796106286658874 http://orcid.org/0000-0003-3317-3955 rafael.bel.silva@seducam.pro.br
Referencing this:

GUIMARÃES, C. S. S.; VAZ, M. A. B.; SILVA, R. B. P.. Aplicações do empreendedorismo na conservação ambiental dos recursos naturais. Revista Ibero Americana de Ciências Ambientais, v.12, n.2, p.591602, 2021. DOI: http://doi.org/10.6008/CBPC21796858.2021 .002 .0051 


\section{INTRODUÇÃO}

Estudar a economia ambiental é pensar no conceito de empreendedorismo social e partir para uma compreensão mais abrangente sobre o conceito de mercado. Pensado em um determinado espaço florestal o qual permite contribuir significativamente para a proteção e a conservação da biodiversidade, da diversidade de ambientes e do patrimônio natural. Tal tipo de estudo, contribui para o equilíbrio ecológico essencial para a boa qualidade de vida e proporcionando benefícios econômicos resultantes do uso direto e indireto dos recursos naturais de forma mais organizativa e sustentável.

Na visão de Dalmoro (2009), o fenômeno da ação antrópica sobre o meio natural constitui-se numa relação complexa, originada por demandas individuais e coletivas, fundamentadas em aspectos culturais, sociais e econômicos, que refletem decisivamente no atual modelo de exploração e manejo dos recursos naturais disponíveis. 0 percurso em direção ao equilíbrio dinâmico dos ecossistemas se expressa no entendimento das questões tanto de ordem biofísica como socioeconômicas.

Destarte, espera-se dispor do empoderamento e do conhecimento dos processos ecológicos no ambiente pesquisado a partir da construção de uma alternativa econômica voltada para o empreendedorismo de base sustentável. Essa propositura, de médio prazo, tem a proposta de uma estratégia que concilie a promoção do desenvolvimento econômico com o uso sustentável dos recursos naturais, viabilizando inclusão social e distribuição de renda e resultando na melhoria da qualidade de vida dessa população.

A chegada da grande crise do modelo econômico do pós-guerra em 1973, quando todo o capitalismo avançado caiu em uma longa e profunda recessão, pela primeira vez a combinação, baixo crescimento e alta inflação, tudo mudou. A partir de então, as ideias neoliberais começaram a ganhar terreno.

Essa crise iniciou um processo de reavaliação das noções do modelo de desenvolvimento capitalista então adotado, dando uma discussão sobre a validade dessas ideias e abrindo um espaço para novas alternativas à encenação. Gradualmente, os governos de quase todos os países europeus, mesmo os menos conservadores, começaram a adotar a fórmula liberal em seus governos.

As décadas de 60 e 70 ficaram marcadas pela intensificação da ansiedade em relação ao ambiente, em especial a saúde e os perigos causados pela poluição industrial, conduzindo a críticas ambientais de crescimento orientado, desenvolvimento convencional e econômico.

O crescimento populacional, a produção de alimentos, o uso de recursos, a poluição e a capacidade de carga do planeta, resultaram no colapso dos ecossistemas, fome e guerra. Os limites ao crescimento, despontando numa "economia de estado estacionário" e no reconhecimento dos limites absolutos para o crescimento econômico, constituíram-se argumento de críticas, emergindo num pensamento para o DS.

De acordo com Sachs (2004) o desenvolvimento sustentável tem como alicerce, fazer um alerta diante da necessidade de incluir o bem-estar das futuras gerações nas decisões tomadas no presente. 0 desenvolvimento sustentável também visa promover o crescimento econômico comprometido com os limites ecossistêmicos e com a melhor equidade social. 
As maiores divergências existentes em torno da problemática do desenvolvimento sustentável residem em saber o que deve ser sustentado e o que deve ser desenvolvido (NRC, 1999). A ideia de Desenvolvimento Sustentável está intimamente ligada com a palavra progresso, que por sua vez está atrelado às tecnologias, máquinas, ciência, dinheiro, poder, indústrias, cidades e, muitas outras formas de produzir riquezas que podemos ou conseguimos realizar. Bercker (1994) cita que se por um lado o progresso é importante à sociedade, para que haja crescimento econômico, por outro lado, é gerador de miséria e de degradação ambiental.

De acordo com Leff (1996), a temática do desenvolvimento sustentável associada ao estudo da economia ecológica, ecologia política e a ética, cidadania e apropriação social da natureza estão presentes em estudos realizados no início da década de 90 . 0 raciocínio balizador desses estudos está no fato de que o aumento da produção de mercadorias estimula a deterioração dos bens naturais comuns.

No que tange, especificamente, aos recursos naturais alguns exemplos de observância e gestão são tratados de maneira mais valorizada. Nos países industrializados, cujas economias são majoritariamente estruturadas sobre a exploração dos recursos naturais, renováveis ou não, a gestão duradoura destes recursos é um desafio crucial em termos de desenvolvimento e luta contra a pobreza.

Um estudo utilizou o conceito de valores históricos, econômicos, sociais e culturais ao dar a definição de recursos naturais, como sendo definidos por elementos materiais ou não, de paisagem geográfica, que não tenham sofrido importantes transformações ou intervenção humana e cuja própria origem é independente do Homem.

O conceito de recursos naturais evoluiu com o desenvolvimento da civilização, sobrevivência e conforto da sociedade em geral. Estes recursos, materiais ou não, cuja própria gênese é independente do homem e aos quais foram atribuídos, historicamente, valores econômicos, sociais e culturais que devem ser compreendidos numa relação homem-natureza, têm sofrido importantes transformações pelo trabalho humano (NOGUEIRA, 1997).

É difícil para a comunidade científica calcular de forma imediata a contribuição econômica e financeira dos recursos naturais para a sociedade. Contudo, é evidente que a vida humana depende diretamente dos mesmos, na medida em que estes fornecem ao ser humano alimentos, água, para além de se constituírem como fonte de muitas outras facilidades para a vida nas sociedades atuais. Estes recursos possuem valor social, cultural e também econômico para a sociedade, na medida em que não fornecem apenas os produtos diretamente extraídos da natureza, mas também uma variedade de ecoserviços.

O sucesso da gestão e conservação dos recursos, na resposta à perda de biodiversidade, requer a seleção do local e a incorporação de medidas locais trade-offs para evitar a má representação de alguns ecossistemas, aliando ainda a necessidade de legislação adequada e de gestão de recursos suficientes.

É de uma necessidade que surge o empreendedorismo sustentável, que tem foco direcionado para a sustentabilidade, permeando não só aspectos econômicos, mas também os sociais e ambientais. Nesse sentido, o empreender somente objetivando a lucratividade é revisto. Mesmo considerando que o fator 
econômico é essencial para a perenidade do negócio, é preciso ir além e pensar no que as organizações produzirão para a sociedade e o meio ambiente (HALL et al., 2010).

Açaizeiro (Euterpe oleraceae Mart) é uma palmeira que ocorre em várias regiões da Amazônia, sendo que a procura pela polpa dos frutos para fabricação de sorvetes, licores, xaropes, etc. vem sendo alavancada devido ao seu delicioso sabor e alto potencial energético. Trata-se de um produto de grande relevância socioambiental e econômica para a região e destaca-se pela grande abundância, facilidade de manejo, importância social e mercado promissor.

Dados do IBGE indicaram que a Região Norte é responsável por 91\% da produção nacional de açaí. No Estado do Pará a produção de frutos sustenta uma cadeia produtiva que envolve dezenas de milhares de famílias, as quais tiram seu sustento desse importante segmento da fruticultura regional.

A análise financeira de indicadores de investimentos para Neves (2002) refere-se à avaliação ou estudo da viabilidade, estabilidade e lucratividade de um negócio ou projeto. Engloba um conjunto de instrumentos e métodos que permitem realizar diagnósticos sobre a situação financeira de uma empresa, assim como prognósticos sobre o seu desempenho futuro.

De posse de tais informações, este trabalho busca analisar o empreendedorismo social como proposta para conservação ambiental dos recursos naturais, relacionando tal ação com a cadeia produtiva do açaí (Euterpe oleraceae), na cidade de Humaitá-AM.

\section{METODOLOGIA}

A presente pesquisa foi realizada através de um estudo de viabilidade econômica e financeira na coleta extrativista de frutos de açaí (Euterpe oleraceae) e o diagnóstico da tomada de decisão do extrativista/empreendedor.

O diagnóstico foi realizado a partir de uma pesquisa exploratória e qualitativa. De acordo com Gil (1999) a pesquisa exploratória caracteriza-se por desenvolver, esclarecer e modificar conceitos e ideias para que sejam formulados problemas mais precisos ou hipóteses para estudos posteriores. Um autor em 1999 cita que os estudos que empregam metodologia qualitativa podem descrever a complexidade de determinado problema, analisar a interação de certas variáveis, compreender e classificar processos dinâmicos vividos por grupos sejam indivíduos ou organizações, resultando também que pode contribuir no processo de mudança de determinados grupos, possibilitando o maior nível de profundidade e entendimento das particularidades do comportamento.

A pesquisa refere-se a uma aplicação de estudo de viabilidade econômica visando a estabelecer diretrizes para introdução de uma discussão empreendedora que venha promover a sustentabilidade e o desenvolvimento. Alguns autores estabeleceram três maneiras de classificação de uma pesquisa cientifica as quais também serviram de base para a classificação da pesquisa desenvolvida neste estudo. Esta classificação é baseada nas seguintes proposições: quanto aos objetivos, quanto à natureza e quanto aos procedimentos adotados. 
A pesquisa bibliográfica pode ser considerada o primeiro passo de toda pesquisa cientifica e apresenta como principal vantagem o fato de permitir ao investigador a cobertura de uma gama de fenômenos muito mais ampla do que aquela que poderia pesquisar diretamente. Não se trata de mera repetição do assunto, mas propicia o exame de um tema sob novo enfoque ou abordagem, podendo chegar a conclusões inovadoras (LAKATOS et al., 1995; GIL, 1999).

A área da pesquisa localiza-se no município de Humaitá, no estado do Amazonas, sob as coordenadas geográficas de $7^{\circ} 30^{\prime} 22^{\prime \prime}$ S e $63^{\circ} 01^{\prime} 15^{\prime \prime}$ W (Figura 1). De acordo com Brasil (1978) as áreas de estudo estão situadas na mesma zona climática, segundo Köppen, pertencendo ao grupo A (Clima Tropical Chuvoso) e tipo climático Am (chuvas do tipo monção), apresentando um período seco de pequena duração. A pluviosidade está limitada pelas isoietas de 2.250 e $2.750 \mathrm{~mm}$, com período chuvoso iniciando em outubro e prolongandose até junho. As temperaturas médias anuais variam entre 25 으 e 27 으 e a umidade relativa fica entre 85 e 90\%. O município de Humaitá-AM, possui área territorial de $33.071,902 \mathrm{~km}^{2}$, e população estimada em 51.354 habitantes.

Entre as principais comunidades destacadas, as que têm maior volume de coleta de açaí são as seguintes: Lago do Antônio, Lago do Uruapiara, Buiuçu, Realidade, Lago do Acará, Distrito de Auxiliadora, Lago do Carapanatuba, Pirapitinga, Moanense, São Miguel, Namor, Cintra, Paraisinho, Paraíso Grande, Flexal, Ipixuna e BR-230.

Foram coletados dados secundários do Instituto de Desenvolvimento Agropecuário e Florestal Sustentável do Estado do Amazonas (IDAM). Os dados foram obtidos de relatório executivo sobre a produção de açaí no Estado do Amazonas, bem como a listagem das principais comunidades da várzea de Humaitá com o volume de produção mais expressivos. Reuniões com executivos de órgãos governamentais foram feitas para a coleta de dados, bem como visitas em sites, uso de jornais e periódicos da área pesquisada. Foram utilizados, ainda, dados da estrutura produtiva da cultura do açaí no Estado do Amazonas e efetuou-se avaliação técnica da implantação/exploração de 1 (um) hectare (ha), com orçamento para espécie considerada nessa pesquisa (Euterpe oleraceae) com as técnicas de espaçamento 5,0 $\mathrm{m} \times 4,0 \mathrm{~m}\left(20 \mathrm{~m}^{2}\right) \mathrm{com}$ aproximadamente 500 plantas/ha, cada uma produzindo em média $20 \mathrm{~kg}$ de frutos/ano. A análise dos fluxos de caixa das análises foi submetida a uma taxa de 10\% a.a. para a unidade.

Entre as principais comunidades pesquisadas no município foram destacadas em volume préprodução, apresentadas em Ton, as seguintes comunidades, listadas na Tabela 1.

Tabela 1: Comunidades destacadas pelo volume de produção.

\begin{tabular}{ll} 
Comunidades & Volume de Produção (t) \\
Lago do Antônio & 420 \\
Lago do Uruapeara & 257,60 \\
Buiuçú & 217,17 \\
Realidade & 280 \\
Lago do Acará & 131,6 \\
Distrito de Auxiliadora & 120,12 \\
T.l. Diahui & 100,8 \\
\hline
\end{tabular}


A análise de viabilidade econômica é uma avaliação com a finalidade de apurar os resultados da aplicação dos investimentos, portanto, uma avaliação da rentabilidade dos investimentos em um projeto ou negócio/empreendimento.

De maneira geral, o projeto ou empreendimento cria valor financeiro se o custo de estruturá-lo e fazê-lo funcionar for menor que a receita gerada no horizonte de tempo analisado. Quanto maiores forem os fluxos de caixa, maior será o valor do projeto, pois mais riqueza ele estará gerando. Portanto, a avaliação de um projeto é realizada em relação às expectativas de geração de fluxo de caixa. Os fluxos de caixa são analisados por meio de indicadores de viabilidade. Um indicador de viabilidade é um dado que mostra se os investimentos realizados inicialmente são rentáveis ou não.

Na visão de Martins et al. (2008) é considerada uma sofisticada técnica de análise de orçamento de capital, exatamente por considerar o valor do dinheiro no tempo. Utilizando-se essa técnica tanto as entradas quanto as saídas de caixa são traduzidas para valores monetários atuais. Dessa forma, podem ser comparadas ao investimento inicial, que está automaticamente expresso em termos monetários atuais.

Valor Presente Líquido é a relação de todos os investimentos realizados e retornos obtidos, calculados em cima de uma taxa de juros e somando-os algebricamente. Este valor é considerado em constantes positivas e negativas. Valores negativos indicam um VPL sem níveis de atratividade sendo um valor com retorno abaixo do mínimo esperado. Para investimentos que obterem um VPL positivo é considerado um projeto com um índice bom de atratividade.

De acordo com Zago et al. (2009) o Valor Presente Líquido de uma proposta de investimento é a soma algébrica, na data zero, dos saldos dos fluxos de caixa descontados à Taxa Mínima de Atratividade, como representado na figura 1.

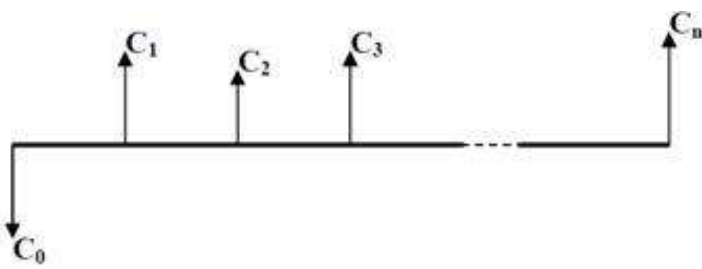

Figura 1: Exemplo de representação gráfica de fluxos de Caixas Descontados.

O VPL descontado como a soma algébrica de todos os fluxos de caixa descontados para o instante presente $(\mathrm{t}=0)$, a uma dada taxa de juros (i): se o VPL é maior ou igual à zero, o investimento é considerado viável; quanto maior for o VPL, maior é o benefício gerado pelo projeto; se o VPL é menor que zero; o investimento é considerado inviável.

Segundo Graça et al. (2000) a Taxa Interna de Retorno (TIR) é o procedimento mais popular para análise de rentabilidade de projetos de investimento. A TIR é a taxa de retorno onde o VPL se iguala à zero. De outra forma, a TIR é a taxa de desconto que faz o VPL de um fluxo de caixa antecipado igualar-se aos custos do projeto e representa o retorno intrínseco do projeto, independente das taxas de juros do mercado. 
Casarotto Filho (2000) define a taxa interna de retorno de um fluxo de caixa a taxa para a qual o valor presente líquido do fluxo é nulo, onde a TIR pode ser usada para analisar a dimensão de retorno como também para analisar a dimensão do risco. Na dimensão de retorno ela pode ser interpretada como um limite superior para a rentabilidade de um projeto de investimento. Porém essa informação só é relevante se, para o projeto em análise, não se souber qual o valor da TMA.

Graça et al. (2000) explica que ao final dos cálculos se a TIR for maior que a TMA o projeto é economicamente viável indicando que há mais ganhos investindo-se no projeto do que na TMA. Caso contrário se menor do que a Taxa Mínima de Atratividade o investimento não é economicamente atrativo, pois seu retorno é superado pelo retorno de um investimento com o mínimo de retorno e se for igual à Taxa Mínima de Atratividade o investimento está economicamente numa situação de indiferença.

A fórmula para calcular a TIR é apresentada na Equação 1:

$$
T I R=\sum_{j=0}^{n} \frac{F C_{j}}{(1+i)^{j}}=0
$$

Equação 1: Fórmula para TIR.

Onde:

TIR: Taxa interna de retorno; FC : Fluxo de caixa líquido no momento $\mathrm{i}$; n: Duração do projeto;

Se a TIR é maior ou igual à TMA, o investimento é considerado viável e acima do esperado pelos empreendedores; se a TIR é menor que a TMA, o investimento é considerado inviável, estando abaixo do retorno esperado.

Um dos métodos, que é muito utilizado, e que possui limitações do ponto de vista conceitual é o payback ou método do tempo de recuperação do investimento. O método do payback consiste do prazo necessário para a recuperação do capital investido, podendo ser simples - quando não se considera o custo de capital e valor do dinheiro no tempo - ou descontado - quando se considera o valor do dinheiro no tempo - podendo ser normalmente recomendado seu uso como critério de desempate, se for necessário após o emprego de um dos métodos exatos (BRUNI et al., 1998).

Considerado por Casarotto Filho et al. (2008) o principal método não exato, mede o tempo necessário para que o somatório das parcelas anuais seja igual ao investimento inicial. Genericamente pode-se dizer que registra o tempo médio para os fluxos de caixa se equiparar ao valor do investimento. E pode ser representado de acordo com a Equação 2:

$$
\text { Payback }=\frac{\text { Valor do Investimento }}{\text { Valor dos Fluxos de Caixa }}
$$

Equação 2: Fórmula para o Payback.

Segundo Souza (2004) esse indicador em contextos dinâmicos, como o de economias globalizadas, assume importância no processo de decisões de investimentos, e já que a tendência é de mudanças contínuas e acentuadas no cenário atual da economia, não se pode esperar muito para recuperar o capital investido sob pena de se alijar das próximas oportunidades de investimentos. Um detalhe muito importante dessa 
metodologia é que ela utiliza os fluxos de caixa nominais do projeto, de forma que o valor que o dinheiro possui no tempo não é levado em conta na análise.

\section{RESULTADOS E DISCUSSÃO}

Segundo dados pesquisados, para implantação da investigação proposta, foi necessária a realização

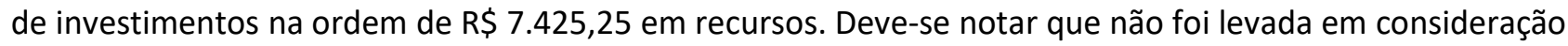
a aquisição da terra, visto que o futuro empreendedor já tem a posse da terra para o plantio.

Tabela 2: Investimentos Totais de Implantação.

\begin{tabular}{|c|c|c|c|c|}
\hline \multicolumn{2}{|l|}{ Capital Fixo } & \multicolumn{3}{|c|}{ Ano 0} \\
\hline Especificação & Unidade de Referência & Custo Unitário (R\$) & Quantidade & Valor Total (R\$) \\
\hline Capital Fixo & \multicolumn{4}{|c|}{$5.358,00$} \\
\hline \multicolumn{5}{|l|}{ Instalações } \\
\hline \multicolumn{5}{|l|}{ Máq. e Equip. } \\
\hline Carro de Mão & Unidade & 190,00 & 2 & 360,00 \\
\hline Enxada & Unidade & 60,00 & 2 & 120,00 \\
\hline Tesoura de Poda & Unidade & 70,00 & 2 & 140,00 \\
\hline Foice & Unidade & 40,00 & 5 & 200,00 \\
\hline Boca de Lobo & Unidade & 80,00 & 7 & 560,00 \\
\hline Terçado & Unidade & 60,00 & 7 & 420,00 \\
\hline Lima p/Amolar & Unidade & 20,00 & 2 & 40,00 \\
\hline Ancinho & Unidade & 30,00 & 2 & 60,00 \\
\hline Mesa & Unidade & 200,00 & 2 & 400,00 \\
\hline Armário & Unidade & 150,00 & 2 & 300,00 \\
\hline $\begin{array}{l}\text { Kit Informática } \\
\text { (Comp.+Imp.+Nobreak) }\end{array}$ & Conjunto & $2.758,00$ & 1 & $2.758,00$ \\
\hline \multicolumn{4}{|l|}{ Custos de Implantação } & $2.094,25$ \\
\hline Preparo da área manual & Pessoa/dia & 10,00 & 24 & 240,00 \\
\hline Marcação/adubação & Pessoa/dia & 10,00 & 3 & 30,00 \\
\hline Aração/gradagem & Pessoa/dia & 40,00 & 2 & 80,00 \\
\hline Plantio & Hora/trat. & 50,00 & & 50,00 \\
\hline Mudas+transporte & Unidade & 2,00 & 488,85 & 977,70 \\
\hline Fertilizantes & Quilo & 50,00 & 2 & 100,00 \\
\hline Formicidas & Quilo & 40,00 & 2 & 80,00 \\
\hline Inseticidas & Litro & 67,28 & 2 & 134,55 \\
\hline Adubo Orgânico & Quilo & 3,00 & 2 & 6,00 \\
\hline Mão de Obra Plantio/tratos & Pessoa/dia & 10,00 & 6 & 60,00 \\
\hline Supervisão/Implantação & $\mathrm{h} /$ Consultor & 8,00 & 42 & 336,00 \\
\hline Total anual & & & & $5.358,00$ \\
\hline Investimento Total & & & & $7.452,25$ \\
\hline
\end{tabular}

Fonte: Adaptado de SUFRAMA.

A tabela 3 descreve os itens necessários à manutenção do plantio, como a mão-de-obra tanto direta quanto indireta necessária para plantio e tratos culturais, este incluído no item diversos por falta de maiores informações da fonte, onde foram coletadas as mesmas. Os cálculos para dia homem (DH), com um turno de trabalho de 8 horas diárias, foram estipulados em base ao rendimento operacional do trabalhador rural.

Tabela 3: Custos de Manutenção(ano a ano).

\begin{tabular}{|c|c|c|c|c|c|c|c|c|c|c|c|c|}
\hline \multirow[t]{3}{*}{ Especificação } & \multirow{3}{*}{$\begin{array}{l}\text { Uni } \\
\text { d. }\end{array}$} & \multirow{3}{*}{$\begin{array}{l}\text { Valor } \\
\text { unitár } \\
\text { io }\end{array}$} & \multicolumn{10}{|c|}{ Valores totais } \\
\hline & & & \multicolumn{2}{|c|}{ Ano 01} & \multicolumn{2}{|l|}{ Ano 02} & \multicolumn{2}{|l|}{ Ano 03} & \multicolumn{2}{|l|}{ Ano 04} & \multicolumn{2}{|l|}{ Ano 05} \\
\hline & & & Quant & Valor & Quant & Valor & Quant & Valor & Quant & Valor & Quant & Valor \\
\hline Custo & & & & Totais & & & & & & & & \\
\hline $1.626,84$ & & & & & 1765,07 & & 1781,23 & & 1700,23 & & 1700,23 & \\
\hline $\begin{array}{l}\text { Mão de } \\
\text { Indireta }\end{array}$ & & & & $\begin{array}{l}1029 \\
64\end{array}$ & & $\begin{array}{l}1029 \\
44\end{array}$ & & $\begin{array}{l}1029 \\
23\end{array}$ & & $\begin{array}{l}1029 \\
44\end{array}$ & & $\begin{array}{l}1029, \\
44\end{array}$ \\
\hline Mão de Obra Direta & & & & 333,5 & & 336,7 & & 405,8 & & 405,8 & & 405,8 \\
\hline & & & & 6 & & 8 & & 9 & & 0 & & 9 \\
\hline
\end{tabular}




\begin{tabular}{|c|c|c|c|c|c|c|c|c|c|c|c|c|}
\hline Despesas Adm. & & & & 58,75 & & 94 & & 141 & & 60 & & 60 \\
\hline Seguros & & & & 13,79 & & 13,79 & & 13,79 & & 13,7 & & 13,79 \\
\hline Depreciação & & & & 63,60 & & 63,60 & & 63,6 & & 63,60 & & 63,60 \\
\hline $\begin{array}{l}\text { Manutenção/Conse } \\
\text { rvação }\end{array}$ & & & & 68,75 & & 68,75 & & 68,75 & & 68,75 & & 68,75 \\
\hline Tributos e Encargos & $\mathrm{R} \$$ & 1,00 & 0 & & 0 & & 0 & & 0 & & 0 & \\
\hline Diversos & $\mathrm{R} \$$ & 0,05 & $\begin{array}{l}1174, \\
90\end{array}$ & 58,75 & $\begin{array}{l}1174, \\
90\end{array}$ & 58,75 & $\begin{array}{l}1174, \\
90\end{array}$ & 58,75 & $\begin{array}{l}1174, \\
90\end{array}$ & 58,75 & $\begin{array}{l}1174, \\
90\end{array}$ & 58,75 \\
\hline
\end{tabular}

Fonte: Adaptado de SUFRAMA.

O Fluxo de Caixa Descontado foi gerado a partir da fixação das despesas e das estimativas de receitas como representado abaixo na Tabela 4.

Tabela 4: Representação dos Fluxos de Caixa Descontados do Projeto do Plantio do Açaí em uma área do Estado do Amazonas.

\begin{tabular}{llll}
\hline Ano & Custo Total (h/ha) & Renda Bruta(R\$/ha) & Renda Líquida \\
\hline 0 & 7452,25 & - & $-7452,25$ \\
1 & 1626,84 & - & $-1626,85$ \\
2 & 1665,07 & - & $-1665,08$ \\
3 & 1781,23 & 2500 & 718,77 \\
4 & 1700,23 & 4000 & 2299,77 \\
5 & 1700,23 & 6000 & 4299,77 \\
6 & 1700,23 & 7500 & 5799,77 \\
7 & 1700,23 & 10000 & 8299,77 \\
8 & 1700,23 & 10000 & 8299,77 \\
9 & 1700,23 & 10000 & 8299,77 \\
10 & 1700,23 & 10000 & 8299,77 \\
\hline
\end{tabular}

Para estimativa das receitas, projetou-se uma produção de $2500 \mathrm{~kg} / \mathrm{ha}$ no quarto ano (onde se inicia a colheita do fruto), $4000 \mathrm{~kg} / \mathrm{ha}$ no $5^{\circ}$ ano, $6000 \mathrm{~kg} / \mathrm{ha}$ no ano $6^{\circ}, 7500 \mathrm{~kg} / \mathrm{ha}$ no ano $7^{\circ}$ e a partir do ano $8^{\circ}$, uma constante de $10000 \mathrm{~kg} / \mathrm{ha}$, estimando uma receita líquida na ordem de $\mathrm{R} \$ 8.300,00$, quando é atingido o pico da produção ( $8^{\circ}$ ano), até o fim do trabalho, estipulado em 10anos. O preço do kg do açaí foi estimado em $R \$ 1,00$, considerando uma média na venda no período de safra das chamadas 'latas', contendo, cada uma, $15 \mathrm{~kg}$, por $\mathrm{R} \$ 15,00$. A estabilização das despesas se dará a partir do $5^{\circ}$ ano.

Ao optar pelo investimento no empreendimento no ramo da fruticultura, mais especificamente na plantação de açaí, as expectativas são que o pequeno empreendedor recupere os investimentos efetuados, ou seja, o VPL, que mede a riqueza gerada por um determinado ativo a valores atuais, foi positivo, e acima do que teria recebido se esse capital tivesse sido aplicado no mercado financeiro a $10 \%$ ao ano, em valores monetários o Valor Presente Líquido calculado foi a importância de $\mathrm{R} \$ \mathbf{1 2 . 5 9 7 , 9 7}$ (doze mil e quinhentos noventa e sete e noventa reais). É importante destacar que esse é um retorno para 1 ha de terra e para um horizonte de 10 anos, isto é, a terra ficará imobilizada por 10 anos e, só depois desse período, poder-se-á pensar em outro uso alternativo para a mesma.

A TIR define um limite para a variação da TMA. Enquanto a TMA (estimada em 10\% ao ano) permanecer inferior à TIR (24 \% a.a.), as expectativas são que haja mais ganho em se investir no projeto do que deixar o dinheiro aplicado recebendo a TMA aplicado no mercado a $10 \%$ ao ano do que o investir no cultivo de 1 hectare do açaí. $O$ resultado sinaliza para um risco financeiro baixo para esse empreendimento.

Com relação à atualização dos fluxos de caixa futuro e a sua relação com o investimento inicial, de acordo com os cálculos o Índice de Lucratividade Líquida retornou um valor de 1,69, isso significa que para 
cada 1 unidade monetária investida, houve uma adição de $\mathrm{R} \$ 0,69$ um dos critérios que torna o projeto economicamente viável já que o ILL é maior que 1(um), desse modo multiplica o valor do investimento e a riqueza advinda do plantio do açaí.

Outro indicador é o VPLa que representa a expectativa de ganho do projeto distribuído em valores equivalentes anuais, para o empreendimento estudado os rendimentos anuais durante a vida útil do projeto foi de $\mathrm{R} \$ 2050,26$ descontados a taxa vigente de $10 \%$ a.a. Este resultado evidencia que a rentabilidade funcione como estímulo à busca de novos posicionamentos competitivos e/ou novos arranjos produtivos.

Para o estudo que está sendo analisado a expectativa é a recuperação do investimento já a partir do $8^{\circ}$ ano, como demonstrado no Gráfico 1.

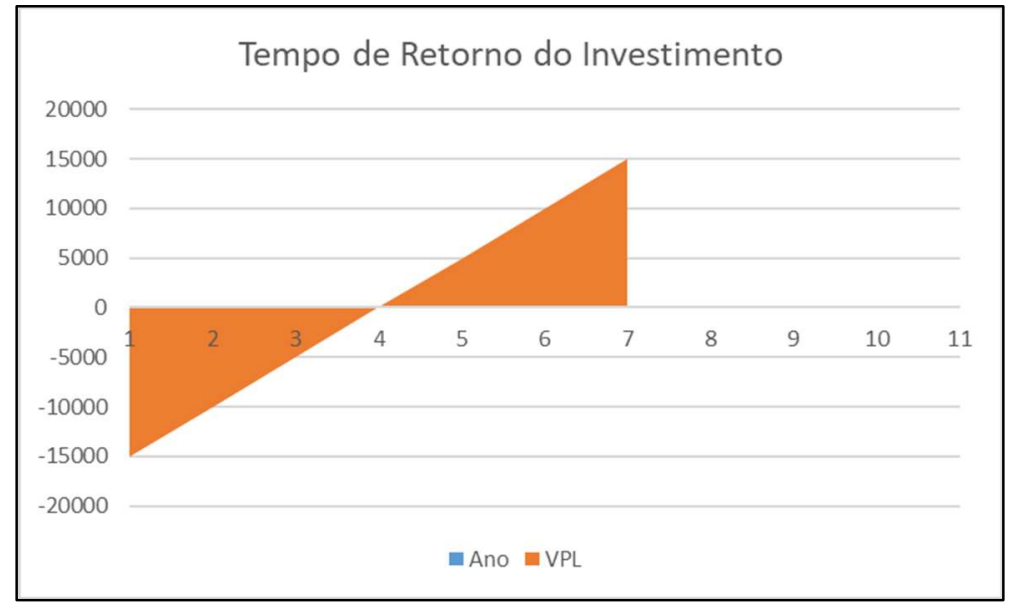

Gráfico 1: Tempo de Retorno do Investimento- Payback - Para um Empreendimento de 1 ha da Cultura de Açaí no Estado do Amazonas. Fonte: Estudo SUFRAMA.

O valor encontrado para o empreendimento açaí sinaliza para um risco considerado um pouco elevado de não recuperação do capital investido, haja vista o período do empreendimento de 10 anos, e o payback após consumir $80 \%$ do tempo total. A produção em 1 ha leva muito tempo para cobrir custos iniciais e dificulta a multiplicação da riqueza.

De acordo com os dados e as informações levantadas no presente trabalho observou-se que é de grande importância a análise da viabilidade econômica, no que diz respeito à produção de produtos locais, como o caso do açaí apresentado, pois as informações levantadas contribuem para um posicionamento diante de que tipo de investimento seria viável ou não realizar.

O interesse pela implantação da produção de frutos tem se dado pelo fato do açaí, antes destinado totalmente ao consumo local, ter conquistado novos mercados e se tornado em importante fonte de renda e de emprego. Segundo o Ministério da Agricultura, Pecuária e Abastecimento a venda da polpa congelada, para outros Estados brasileiros, vem aumentando significativamente com taxas anuais superiores a $30 \%$, podendo chegar à cerca de 12 mil toneladas. As exportações de polpa ou na forma de mix, para outros países, ultrapassam a mil toneladas por ano.

Dessa forma, analisou-se o valor presente líquido (VPL) que gerou uma riqueza de $\mathrm{R} \$ 12.597,97$ durante a vigência do estudo (10 anos), mostrando por sua vez viabilidade na execução do projeto para cada unidade de produção de um hectare, em relação à Taxa Interna de Retorno (TIR) atingida de $24 \%$ a.a., 
demonstra que cobriu os custos de oportunidade, ou Taxa Mínima de Atratividade(TMA) de 10\% a.a. assim reforçando agora na forma de um valor percentual, não mais em um índice monetário, a viabilidade do projeto indicando que a rentabilidade, por período, é maior do que a rentabilidade mínima exigida para o produtor rural.

O incentivo à produção da cultura do açaí para 1 ha é desaconselhável porque produz uma renda de $\mathrm{R} \$ 2050,26$ por ano na média de cada unidade de produção de 1 ha, ou seja, uma renda média mensal de apenas $R \$ 170,86$ garantindo apenas a subsistência dos produtores rurais envolvidos na produção, além de outros indicadores que dificultariam a sustentabilidade da produção, entre os quais o Payback em aproximadamente 8 anos, comprometendo parte dos rendimentos e consumido quase $80 \%$ da vida útil do projeto, que é de 10 anos, para liquidar o investimento inicial, ainda que este não seja considerado elevado, mas para a condição de produtor a renda é significativa.

O estudo comprovou que o projeto é viável em uma estrutura de produção de um hectare, porém no período de 10 anos estipulado pelo projeto, mostrou uma demora para que o valor do investimento inicial seja ressarcido, além do baixo retorno mensal médio gerado, o que dificultaria a sustentabilidade da produção.

\section{CONCLUSÕES}

A pesquisa procurou demonstrar que o empreendedorismo atrelado às técnicas de análise econômicas antecipadas pode assegurar um aumento de renda dos produtores e coletores que já praticam o extrativismo de produtos florestais não madeireiros no Estado do Amazonas.

A conservação da melhor utilização dos recursos naturais, através do fortalecimento de determinada cadeia produtiva, aqui destacado o açaí, deverá promover o desenvolvimento sustentável e produtivo também da agricultura familiar na região, contribuindo para o aumento do valor agregado do produto e para a geração de renda, melhorando a qualidade de vida e promovendo o empreendedorismo de negócios sustentáveis.

Destarte, a sugestão da estrutura de um plano de negócio completo, passando por uma breve análise de viabilidade econômica e financeira, constitui-se em um potencial instrumento para o desenvolvimento econômico e social. O Planejamento, como ficou destacado é essencial para os empreendedores extrativistas, pois os prepara para um olhar de futuro de melhores práticas de sustentabilidade ambiental.

\section{REFERÊNCIAS}

BERCKER, K. B.. Geopolítica da Amazônia. Estudos Avançados, v.19, n.53, p.71-86, 1994.

BRUNI, A. L.; FAMÁ, R.; SIQUEIRA, J. O.. Análise do risco na avaliação de projetos de investimento: uma aplicação do método de Monte Carlo. Caderno de Pesquisas em Administração, v.1, n.6, p.62-75, 1998.

CASAROTTO FILHO, N. C.; KOPITTKE, B. H.. Análise de Investimentos. 10 ed. São Paulo: Atlas, 2008.
CASAROTTO FILHO, N. C.. Análise de Investimentos: matemática financeira, engenharia econômica, tomada de decisão, estratégia empresarial. 9 ed. São Paulo: Atlas, 2000.

DALMORO, M.. A visão da sustentabilidade na atividade empreendedora: uma análise a partir de empresas incubadas. Revista Gestão Organizacional, v.2, n.1, p.87104, 2009.

GIL, A. C.. Como Elaborar Projetos de Pesquisa. 4 ed. São Paulo: Atlas, 2002 
GRAÇA, L. R.; RODIGHERI, H. R.; CONTO, A. J.. Custos florestais de produção: conceituação e aplicação. Colombo: Embrapa Florestas, 2000.

HALL, J. K.; DANEKE, G. A.; LENOX, M. J.. Sustainable development and entrepreneurship: past contributions and future directions. Journal of Business Venturing, v.25, n.5, p.439-448, 2010.

LAKATOS, E. M.; MARCONI, M. A.. Técnicas de Pesquisa: planejamento e execução de pesquisas, amostragens e técnicas de pesquisas, elaboração, análise e interpretação de dados. 5 ed. São Paulo: Atlas, 2002.

LEFF, E.. Saber ambiental: sustentabilidade, racionalidade, complexidade, poder. Petrópolis: Vozes, 1996.

MARTINS, M. A.; PESSOA, J. D. C.; GONÇALVES, P. S.; SOUZA, F. I.; MATTOSO, L. H. C.. Thermal and mechanical properties of the açaí fiber/natural rubber composites. Journal of materials science, v.43, n.19, p.6531-6538, 2008. DOI: http://doi.org/10.1007/s10853-008-2842-4
NRC. National Research Council. Mudanças e agressões ao meio ambiente: como a busca de melhoria e condições de vida dos homens tem contribuído para as mudanças ambientais em todo o mundo. São Paulo: Makron Books do Brasil, 1993.

NEVES, J. C.. Análise Financeira. Lisboa, 2002.

NOGUEIRA, J. M.; MARCELINO A. A. M.. Quanto vale aquilo que não tem valor? Valor de existência, economia e meio ambiente. In: ENCONTRO BRASILEIROS DE ECONOMIA (ANPEC), 25. Anais. Recife, 1997.

SACHS, I.. Experiências internacionais de um cientista inquieto. Estudos Avançados, v.18, n.52, p.353, 2004.

SOUZA, A.. Decisões financeiras e análise de investimentos: fundamentos, técnicas e aplicações. 5 ed. São Paulo: Atlas, 2004.

ZAGO, C. A.; WEISE, A. D.; HORNBURG, R. A.. A importância do estudo de viabilidade econômica de projetos nas organizações contemporâneas. In: CONVIBRA - CONGRESSO VIRTUAL BRASILEIRO DE ADMINISTRAÇÃO, 6. Anais. Rio de Janeiro, 2009.

A CBPC - Companhia Brasileira de Produção Científica (CNPJ: 11.221.422/0001-03) detém os direitos materiais desta publicação. Os direitos referem-se à publicação do trabalho em qualquer parte do mundo, incluindo os direitos às renovações, expansões e disseminações da contribuiç̃o, bem como outros direitos subsidiários. Todos os trabalhos publicados eletronicamente poderão posteriormente ser publicados em coletâneas impressas sob coordenação da Sustenere Publishing, da Companhia Brasileira de Produção Científica e seus parceiros autorizados. Os (as) autores (as) preservam os direitos autorais, mas não têm permissão para a publicação da contribuição em outro meio, impresso ou digital, em português ou em tradução. 